Research Article

\title{
Sintering Behavior and Properties of Mo-Cu Composites
}

\author{
Aokui Sun (D), ${ }^{1}$ Yuejun Liu, ${ }^{1}$ Dezhi Wang, ${ }^{2}$ and Zhihua Zhou ${ }^{3}$ \\ ${ }^{1}$ Key Laboratory of Advanced Packaging Materials and Technology of Hunan Province, \\ School of Packaging and Materials Engineering, Hunan University of Technology, Zhuzhou 412007, China \\ ${ }^{2}$ School of Materials Science and Engineering, Central South University, Changsha 410083, China \\ ${ }^{3}$ Key Laboratory of Controlled Preparation and Functional Application of Fine Polymer of Hunan Province, \\ Hunan University of Science and Technology, Xiangtan 411100, China
}

Correspondence should be addressed to Aokui Sun; aksun@hut.edu.cn

Received 25 March 2018; Accepted 20 May 2018; Published 25 July 2018

Academic Editor: Guillaume Bernard-Granger

Copyright (๑ 2018 Aokui Sun et al. This is an open access article distributed under the Creative Commons Attribution License, which permits unrestricted use, distribution, and reproduction in any medium, provided the original work is properly cited.

A simple microwave-assisted aqueous solution strategy combined with a subsequent low-temperature hydrogen reduction process was used to prepare $\mathrm{Mo}-\mathrm{Cu}$ nanopowders. In order to systematically investigate the densification behavior and properties of Mo-Cu composites, the densification, microstructure, hardness, electrical conductivity, thermal conductivity, and bending strength of $\mathrm{Mo}-\mathrm{Cu}$ compacts were tested after sintering at different temperatures. Results show that the sintering temperature is a critical factor in the densification process of $\mathrm{Mo}-\mathrm{Cu}$ composites. The shrinkage rate, density, and hardness of sintered composites increase as the temperature rises. However, too high sintering temperature resulted in the decrease in electrical conductivity (EC), thermal conductivity (TC), and bending strength. By optimizing all the performance indicators, high-performance Mo- $25 \mathrm{wt} . \% \mathrm{Cu}$ composites with a homogeneous microstructure accompanied with good physical and mechanical properties could be successfully obtained by sintering for $2 \mathrm{~h}$ at $1200^{\circ} \mathrm{C}$.

\section{Introduction}

Owing to the outstanding physical and mechanical properties (e.g., satisfactory electrical and thermal conductivity, low and adjustable coefficient of thermal expansion, wear resistance, and high temperature strength) of $\mathrm{Mo}-\mathrm{Cu}$ composites with different copper contents, they are now broadly used for the heavy duty service contacts [1]. Infiltration of molten/liquid copper into the preformed molybdenum skeleton is a conventional process to fabricate the Mo-Cu composites. Nevertheless, Mo-Cu composites with high density can be obtained in this way on account of the mutual insolubility between molybdenum and copper or the high contact angle between liquid copper and molybdenum $[2,3]$. In the last few years, a chemical-activated sintering process has been conducted to improve the sinterability by adding a certain amount of the metal activator into $\mathrm{Mo}-\mathrm{Cu}$ powders. Nevertheless, these activators (such as $\mathrm{Co}, \mathrm{Ni}$, or $\mathrm{Fe}$ ) exhibit a passive effect on the electrical and thermal properties of the $\mathrm{M}-\mathrm{Cu}$ composites $(\mathrm{M}=\mathrm{W}, \mathrm{Mo})$ [4-7].
Considering that the sintering activity of most powders can be modified by decreasing the particle size and enhancing the homogeneity of the starting powders, many researches have been performed recently to prepare superfine (even nanoscale) Mo-Cu powders [8-11]. Many attempts have been tried to prepare these powder systems in different ways, such as the heterogeneous precipitation process [12], gas-phase synthesis [13], mechanical alloying process $[14,15]$, and nitridation-denitridation method [16]. However, the quantity and content of published works in this area do not seem sufficient to draw a plausible conclusion about successfully preparing $\mathrm{Mo}-\mathrm{Cu}$ powders with good sinterability and $\mathrm{Mo}-\mathrm{Cu}$ composite compacts with excellent performance.

In our previous study [17], well-dispersed Mo-Cu nanopowders were synthesized by a simple and time-saving route. The densification behavior and properties of $\mathrm{Mo}-\mathrm{Cu}$ powders obtained in this way are investigated in the present research. Effects of temperature on the microstructures and properties are also systemically studied in this work. 


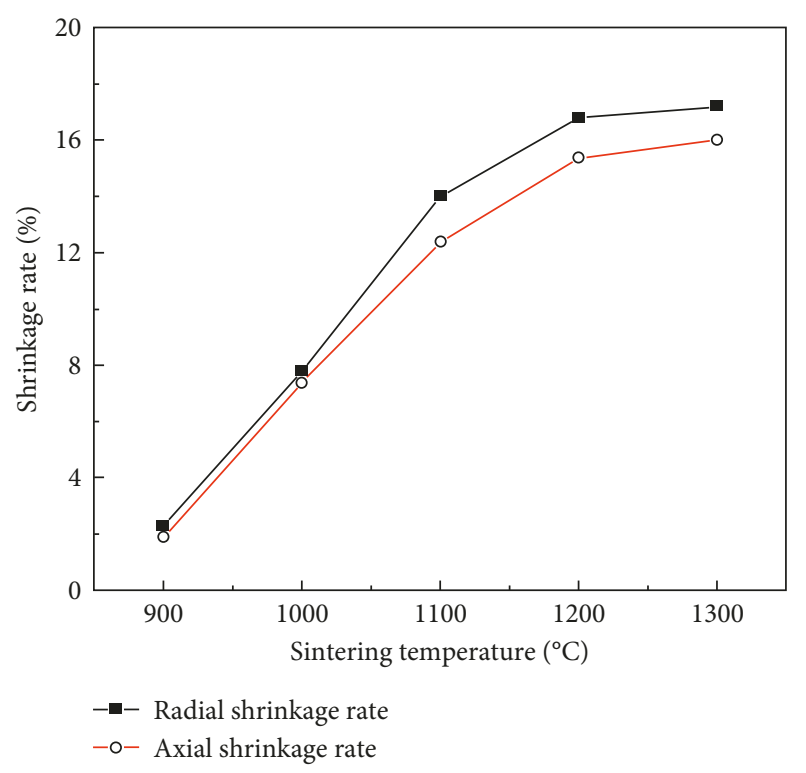

FIGURE 1: Effect of sintering temperature on shrinkage of sintered compacts.

\section{Experimental Procedure}

Initially, hexaammonium heptamolybdate tetrahydrate and copper(II) nitrate trihydrate at a designed weight ratio were dissolved in deionized water to obtain mixed salt solution. After that, excessive ammonia solution was instilled into the salt solution till no precipitate and gel left. This obtained solution was heated in a microwave oven to evaporate all liquid, and then, the dry precipitates were collected and reduced at $650^{\circ} \mathrm{C}$ for $2 \mathrm{~h}$ to obtain $\mathrm{Mo}-\mathrm{Cu}$ composite powders. The as-prepared $\mathrm{Mo}-\mathrm{Cu}$ composite powders were compacted in a steel die under the pressure of $250 \mathrm{MPa}$ to produce green parts. The compacts were sintered at $900 \sim 1300^{\circ} \mathrm{C}$ under reducing atmosphere of Ar-20 vol.\% $\mathrm{H}_{2}$ in a tube-type resistance furnace for 2 hours, and the heating rate is $10 \pm 6 \%{ }^{\circ} \mathrm{C} \cdot \mathrm{min}^{-1}$. Then, the sintered samples were cooled to the room temperature $\left(20^{\circ} \mathrm{C}\right)$ through free cooling.

The actual density of sintered Mo-Cu composites was measured using Archimedes' principle. The samples were weighed in air and when immersed in distilled water, and the masses of the thoroughly wetted sample were also measured. An AR5120 electronic balance with an accuracy of $0.0001 \mathrm{~g}$ was used for recording the weights. Theoretical densities of the samples were calculated using the rule-of-mixture principle. Microscopic morphology observations were conducted on an FEI Sirion 200 scanning electron microscope (SEM). The electrical conductivity was measured by the four-point probe method on the HL5500PC Hall effect measurement system. Hardness was measured using an HVD-1000 Vickers hardness tester (by LaiZhou Hardness Tester Corp., China). Bending strength was examined using a mechanics tester of materials (Instron 3369, US). The thermal conductivity was calculated through the following formula:

$$
\lambda=\alpha \rho C_{\mathrm{p}}
$$

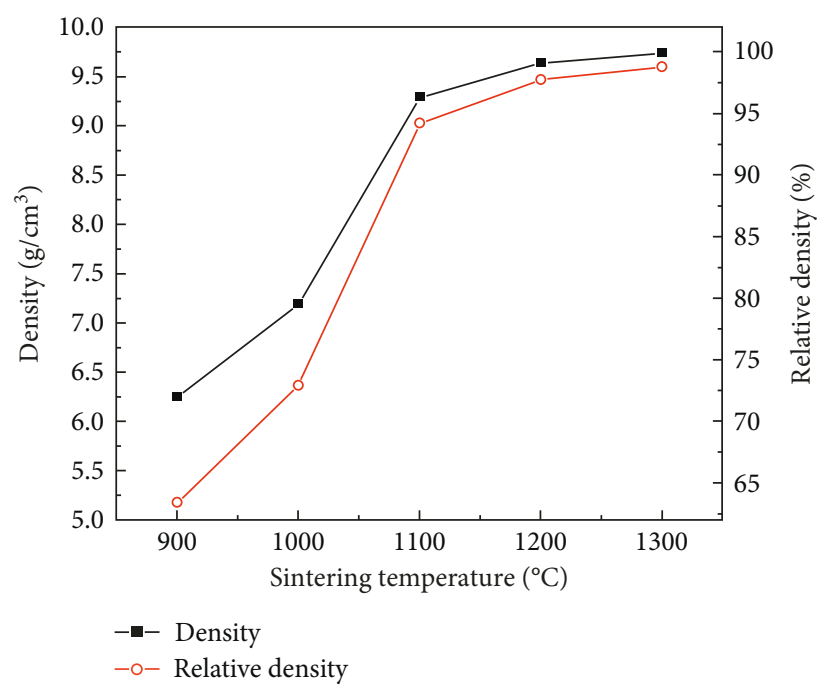

FIGURE 2: Effect of sintering temperature on density and relative density of sintered compacts.

where $\rho$ and $C_{\mathrm{p}}$ are the density and specific heat capacity of the sample, respectively, and $\alpha$ is the thermal diffusivity of the sample and was measured by the thermal diffusivity analyzer (STA449C/3/MFC/G, Netzsch Corporation, Germany). The $C_{p}$ values were calculated based on the rule-ofmixture principle. The detailed equation is as follows:

$$
C_{\mathrm{p}}=\omega_{\mathrm{Cu}} \cdot C_{\mathrm{Cu}}+\omega_{\mathrm{Mo}} \cdot C_{\mathrm{Mo}}
$$

where $\omega_{\mathrm{Cu}}$ and $\omega_{\mathrm{Mo}}$ are the mass fractions of $\mathrm{Cu}$ and Mo in Mo-Cu composites, respectively. $C_{\mathrm{Cu}}\left(0.38 \mathrm{~J} \cdot \mathrm{g}^{-1} \cdot \mathrm{K}^{-1}\right)$ and $C_{\mathrm{Mo}}\left(0.25 \mathrm{~J} \cdot \mathrm{g}^{-1} \cdot \mathrm{K}^{-1}\right)$ are specific heat capacities at a constant pressure of $\mathrm{Cu}$ and $\mathrm{Mo}$, respectively [18].

\section{Results and Discussion}

3.1. Sintering Behavior. Figure 1 shows the influence of sintering temperature on shrinkage. It is well known that as sintering temperature rises, the contact area between particles increases, evolving into the sintering neck. Continuous growth of the sintering neck leads to diminishment or vanishment of pores between particles and the increase of shrinkages. It is worth noting that the radial shrinkage of Mo-Cu composites is always higher than the axial shrinkage. This is because one-direction compacting is used to obtain the green compacts, so the radial pressure is invariably lower than the axial pressure during the uniaxial pressing process, causing that the shrinkage along radial direction is always easier to be accomplished than that of axial direction.

Figure 2 depicts the effect of sintering temperature on density and relative density of sintered compacts. It can be clearly seen that both the density and the relative density of the sintered samples are dramatically increased by increasing the sintering temperature at the anterior half segment of the whole sintering process. However, when the temperature goes beyond $1100^{\circ} \mathrm{C}$, the growth in density and relative density becomes slow. The solid-phase sintering is conducted 

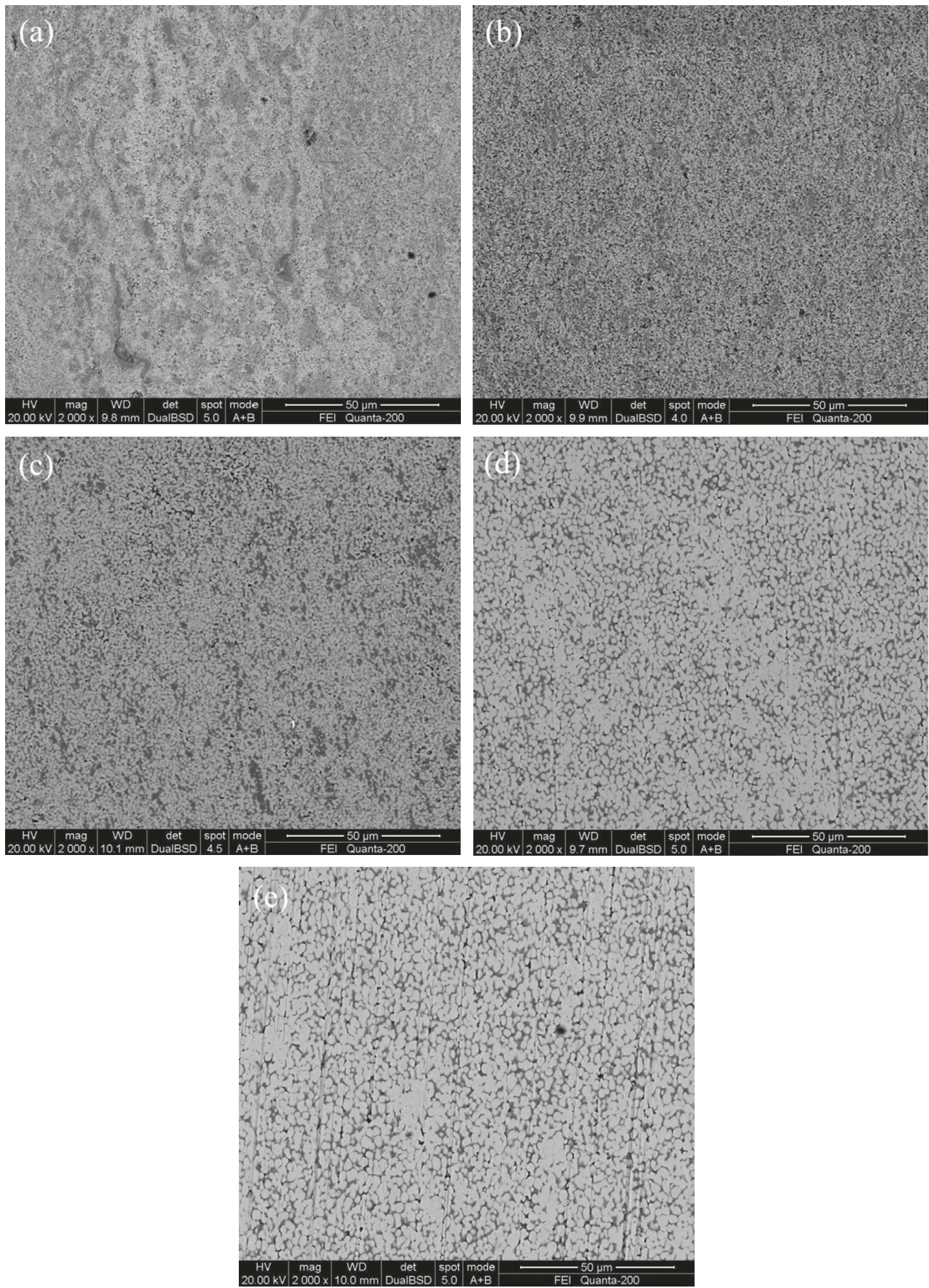

Figure 3: Cross-sectional microstructure of Mo-Cu compacts at different sintering temperatures: (a) $900^{\circ} \mathrm{C}$, (b) $1000^{\circ} \mathrm{C}$, (c) $1100^{\circ} \mathrm{C}$, (d) $1200^{\circ} \mathrm{C}$, and (e) $1300^{\circ} \mathrm{C}$.

at $900^{\circ} \mathrm{C}$ and $1000^{\circ} \mathrm{C}$ because the sintering temperatures are below the melting point of copper $\left(1083^{\circ} \mathrm{C}\right)$. During this process, atomic diffusion ability is enhanced, resulting in the increase of the contact area between particles, the decrease of pores, and the formation and growing of sintering necks, and then, all the above phenomena lead to the increase of the density and the relative density of specimens. When the temperature exceeds the melting point of copper $\left(1100^{\circ} \mathrm{C}\right)$, a bridged copper network all over the structure is gradually formed by bonding and linking of the liquid $\mathrm{Cu}$ phase from different composite particles. Formation of this network can improve the densification $[8,19]$. As a consequence, a significant growth of the densification can be observed as the temperature increased. Nevertheless, the increase in density becomes slow when sintered at $1200^{\circ} \mathrm{C}$ and $1300^{\circ} \mathrm{C}$ (liquid-phase sintering), even though remarkable shrinkage of the Mo-Cu samples can be noticed (Figure 1). Reasons for this phenomenon are concluded as follows: Firstly, there are some impurities in Mo-Cu composite powders, and some of them vaporize into gases during 

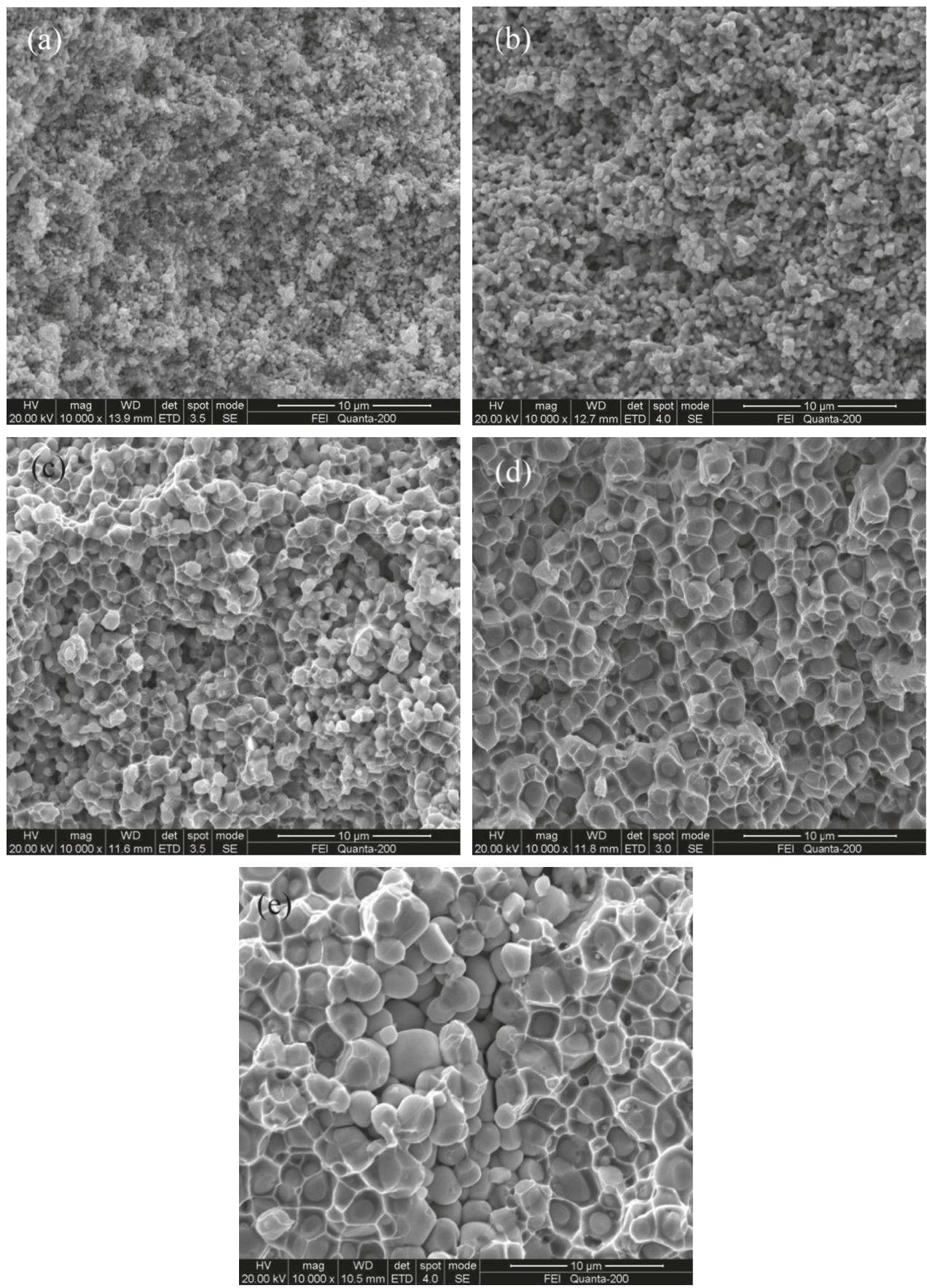

Figure 4: Fractograph of Mo-Cu compacts at different sintering temperatures: (a) $900^{\circ} \mathrm{C}$, (b) $1000^{\circ} \mathrm{C}$, (c) $1100^{\circ} \mathrm{C}$, (d) $1200^{\circ} \mathrm{C}$, and (e) $1300^{\circ} \mathrm{C}$.

sintering at the temperatures. These gases are encapsulated in the samples under the compacting pressure, and volume of them is getting bigger and bigger when the sintering temperature rises, leading to reverse densification. Secondly, when the sintering temperature is higher than the melting point of copper, the large seepage of liquid copper will give birth to many pores, resulting in the decrease in density growth.

In some researches $[20,21]$, the relative density of $\mathrm{Mo}-\mathrm{Cu}$ composites is ranging from 92 to $97 \%$ (relatively low), even though the compacts are sintered at a higher temperature with more sintering time than those in this research. In contrast, the relative density of $\mathrm{Mo}-\mathrm{Cu}$ composites reaches up to $98 \%$ after sintering at $1200^{\circ} \mathrm{C}$ for $2 \mathrm{~h}$ from Figure 2. One possible reason may ascribe to the excellent sintering ability of $\mathrm{Mo}-\mathrm{Cu}$ powders obtained from the microwave-assisted method: Mo-Cu powders are synthesized at a very low temperature, and the small grain size and uniform size distribution give birth to the good powder activity for $\mathrm{Mo}-\mathrm{Cu}$ powders; furthermore, the distinctive copper-core/molybdenum-shell structure of powders obtained by the microwave-assisted method can effectively 
prevent the growth of $\mathrm{Cu}$ grain and agglomeration of $\mathrm{Cu}$, which further facilitates the densification [17].

3.2. Microstructure. The Cross-sectional microstructure of $\mathrm{Mo}-\mathrm{Cu}$ compacts sintered for $2 \mathrm{~h}$ at temperatures ranging from $900^{\circ} \mathrm{C}$ to $1300^{\circ} \mathrm{C}$ is shown in Figure 3. The results demonstrate that the temperature has a significant effect on the sintering response of the $\mathrm{Mo}-\mathrm{Cu}$ composites studied here. From Figure 3(a), it can be clearly seen that there are plenty of large interparticle pores on the cross section of the specimen sintered at $900^{\circ} \mathrm{C}$, and even some particle-like structures can be observed, indicating insufficient sintering reaction at this temperature. As the temperature rises, the porosity of Mo-Cu composites is significantly decreased and the microstructure becomes more homogeneous (Figures $3(b)-3(d))$. When the sintering temperature rises up to $1200^{\circ} \mathrm{C}$, the diffusion of the $\mathrm{Cu}$ phase is enhanced because of the good liquidity of molten copper. Furthermore, the bonding and linking of the liquid $\mathrm{Cu}$ phase makes the distribution of $\mathrm{Cu}$ more uniform. However, too high sintering temperature $\left(1300^{\circ} \mathrm{C}\right)$ gives rise to serious copper evaporation and generation of massive pores and bigger particles (Figure 3(e)).

To further gain insight into the microstructure of Mo$\mathrm{Cu}$ composites, the fractograph of the samples is studied, as shown in Figure 4. One can notice that the particle size is particularly small when sintered at low temperatures (Figures 4(a) and 4(b)). The grain size increases obviously as the sintering temperature increases, as shown in Figures $4(\mathrm{c})$ and 4(d). Additionally, an interconnected network of copper can be seen apparently because the liquid copper phase diffuses easily between Mo particles when sintered at $1100^{\circ} \mathrm{C}$ and $1200^{\circ} \mathrm{C}$. By and large, every Mo particle is capsulated in the continuous network structure of $\mathrm{Cu}$. This network structure, an ideal sintering state, is beneficial to the overall performance of $\mathrm{Mo}-\mathrm{Cu}$ composites, including hardness, strength, electrical conductivity, and thermal conductivity. Nevertheless, a mass of defects, such as pores and uneven distribution of the $\mathrm{Cu}$ phase, are resulted from too high sintering temperature $\left(1300^{\circ} \mathrm{C}\right.$; Figure $\left.4(\mathrm{e})\right)$, which is consistent with the aforementioned result from Figure 3(e).

\subsection{Properties}

3.3.1. Hardness. Figure 5 presents the influence of sintering temperature on the hardness of $\mathrm{Mo}-\mathrm{Cu}$ composites. It is evident that the Vickers hardness is dramatically increased by increasing the sintering temperature at the beginning of the sintering process, but too high temperature has slowed down the growth of hardness. This variation trend is extremely similar to that of density (Figure 2). Evidently, the high density of the sintered samples is the main reason for high hardness. The decrease in porosity of the specimens and the increase in grain size make the Vickers hardness reach up to $219 \mathrm{HV}$ when sintered at $1200^{\circ} \mathrm{C}$.

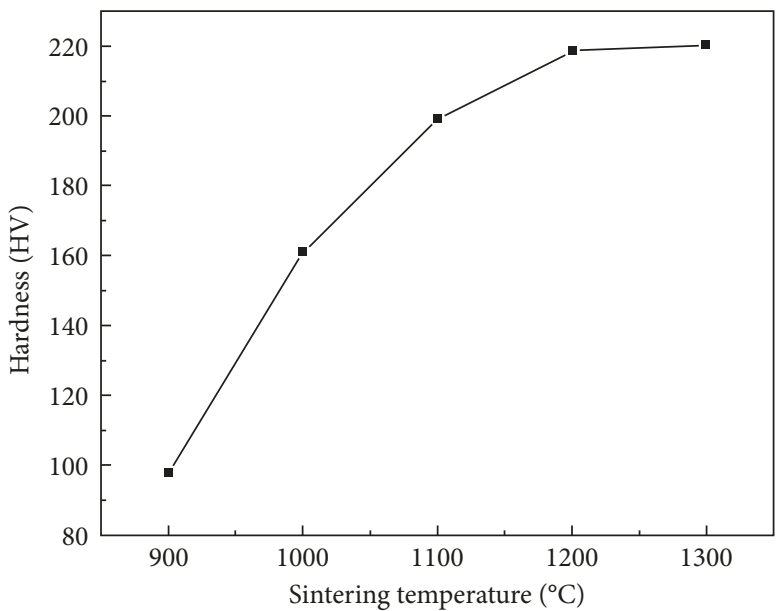

Figure 5: Hardness of $\mathrm{Mo}-\mathrm{Cu}$ composites versus sintering temperature.

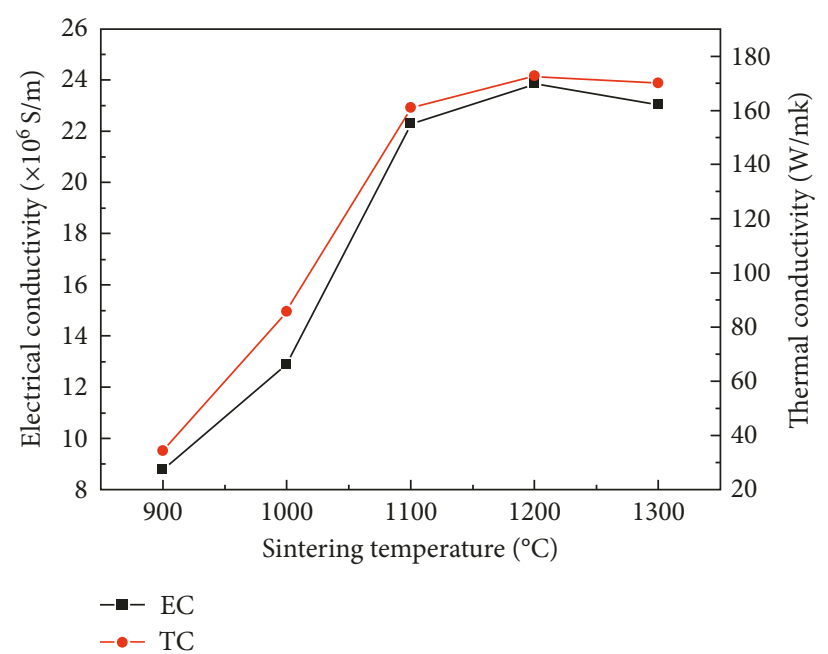

Figure 6: EC and TC of $\mathrm{Mo}-\mathrm{Cu}$ composites versus sintering temperature.

3.3.2. Electrical Conductivity and Thermal Conductivity. Figure 6 depicts the variation of electrical conductivity (EC) and thermal conductivity (TC) of Mo-Cu composites with different temperatures. The results show that both the electrical conductivity and the thermal conductivity increase gradually from $900^{\circ} \mathrm{C}$ to $1200^{\circ} \mathrm{C}$, while a slight decrease can be found in both of them when the sintering temperature rises to $1300^{\circ} \mathrm{C}$. It is known that the $\mathrm{Cu}$ phase inherently has a much higher electrical conductivity and thermal conductivity than molybdenum; hence, a continuous network structure of $\mathrm{Cu}$ formed at $1200^{\circ} \mathrm{C}$ (Figure $4(\mathrm{~d})$ ) makes the electricity and heat transfer promptly between $\mathrm{Mo}$ and $\mathrm{Cu}$. However, too high sintering temperature $\left(1300^{\circ} \mathrm{C}\right)$ results in serious copper evaporation and generation of massive pores, which causes the decrease in both the electrical conductivity and the thermal conductivity. The highest values for EC and TC are obtained when the sintering temperature reaches 


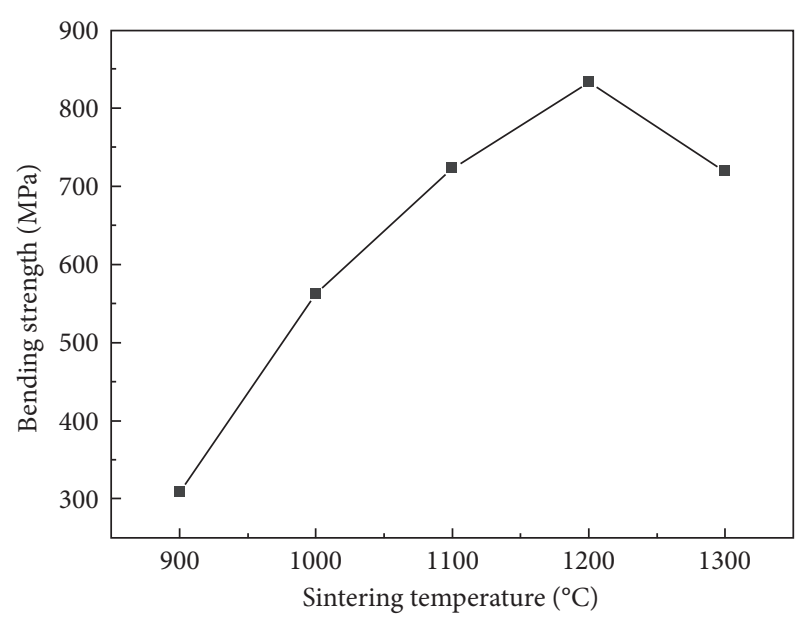

Figure 7: Bending strength of Mo-Cu composites versus sintering temperature.

$1200^{\circ} \mathrm{C}$, which are $23.9 \times 10^{6} \mathrm{~S} \cdot \mathrm{m}^{-1}$ and $172.6 \mathrm{~W} \cdot \mathrm{m}^{-1} \cdot \mathrm{K}^{-1}$, respectively.

3.3.3. Bending Strength. Figure 7 shows the bending strength of composites prepared at different temperatures. At the beginning, the bending strength increases gradually with the increase of sintering temperature and reaches the maximum value of $847 \mathrm{MPa}$ at $1200^{\circ} \mathrm{C}$. Nevertheless, a sharp decline in bending strength can be evidently observed when the temperature climbs above $1200^{\circ} \mathrm{C}$. Therefore, it can be seen that the bending strength, EC, and TC of $\mathrm{Mo}-\mathrm{Cu}$ composites have almost the same trend. As is known, the improvement of relative density leads to the bending strength enhancement with the processing parameter optimization [22]. From Figure 2, it can be seen that composites obtained at $1300^{\circ} \mathrm{C}$ show higher relative density than that at $1200^{\circ} \mathrm{C}$. But losses of the copper network structure and emergence of pores (Figure 4(e)) lead to the decrease of bending strength.

\section{Conclusion}

In summary, $\mathrm{Mo}-\mathrm{Cu}$ composites with excellent properties are prepared by sintering $\mathrm{Mo}-\mathrm{Cu}$ nanoparticles synthesized from a microwave-assisted method. The results show that the sintering temperature is a critical factor in the densification process of $\mathrm{Mo}-\mathrm{Cu}$ composites. The shrinkage, density, relative density, hardness, electrical conductivity, thermal conductivity, and bending strength increase with the rise of sintering temperatures. However, too high temperature results in the decrease in electrical conductivity, thermal conductivity, and bending strength. As a consequence, Mo$\mathrm{Cu}$ composites sintered at $1200^{\circ} \mathrm{C}$ have the optimal microstructure and desired properties. The relative density, hardness, electrical conductivity, thermal conductivity, and bending strength of composites obtained at this temperature are $98 \%, 219 \mathrm{HV}, 23.9 \times 10^{6} \mathrm{~S} \cdot \mathrm{m}^{-1}, 172.6 \mathrm{~W} \cdot \mathrm{m}^{-1} \cdot \mathrm{K}^{-1}$, and $847 \mathrm{MPa}$, respectively.

\section{Data Availability}

All the data used to support the findings of this study are available from the corresponding author upon request (aksun@hut.edu.cn).

\section{Conflicts of Interest}

The authors declare that they have no conflicts of interest.

\section{Acknowledgments}

This work is supported by the National Natural Science Foundation of China (no. 51704108), the Natural Science Foundation of Hunan Province (no. 2018JJ3126), China, and the Key Laboratory Open Foundation of Hunan Province (no. FP201704).

\section{References}

[1] S. H. Hong, B. K. Kim, and Z. A. Munir, "Synthesis and consolidation of nanostructured W-10-40 wt.\% $\mathrm{Cu}$ powders," Materials Science and Engineering: A, vol. 405, no. 1-2, pp. 325-332, 2005.

[2] J. Cheng, P. Song, Y. Gong, Y. Cai, and Y. Xia, "Fabrication and characterization of $\mathrm{W}-15 \mathrm{Cu}$ composite powders by a novel mechano-chemical process," Materials Science and Engineering: A, vol. 488, no. 1-2, pp. 453-457, 2008.

[3] F. A. D. Costa, A. G. P. D. Silva, and U. U. Gomes, "The influence of the dispersion technique on the characteristics of the W-Cu powders and on the sintering behavior," Powder Technology, vol. 134, no. 1-2, pp. 123-132, 2003.

[4] S. S. Ryu, Y. D. Kim, and I. H. Moon, "Dilatometric analysis on the sintering behavior of nanocrystalline W-Cu prepared by mechanical alloying," Journal of Alloys and Compounds, vol. 335, no. 1-2, pp. 233-240, 2002.

[5] I. Ştefan, N. Claudiu, and M. Gavrila, "Influences of the elaboration conditions and addition of $\mathrm{Ni}$ and $\mathrm{Co}$ on the some properties of the W-Cu electrical contacts," Materials Science Forum, vol. 672, pp. 276-280, 2011.

[6] P. A. Chen, G. Q. Luo, Q. Shen, M. J. Li, and L. M. Zhang, "Thermal and electrical properties of $\mathrm{W}-\mathrm{Cu}$ composite produced by activated sintering," Materials and Design, vol. 46, no. 4, pp. 101-105, 2013.

[7] F. Dore, S. Lay, N. Eustathopoulos, and C. H. Allibert, "Segregation of Fe during the sintering of doped W-Cu alloys," Scripta Materialia, vol. 49, no. 3, pp. 237-242, 2003.

[8] D. G. Kim, K. W. Lee, S. T. Oh, and Y. D. Kim, "Preparation of $\mathrm{W}-\mathrm{Cu}$ nanocomposite powder by hydrogen-reduction of ball-milled $\mathrm{W}$ and $\mathrm{CuO}$ powder mixture," Materials Letters, vol. 58, no. 7-8, pp. 1199-1203, 2004.

[9] N. Yang, Z. Wang, L. Chen, Y. Wang, and Y. Zhu, "A new process for fabricating $\mathrm{W}-15 \mathrm{wt} . \% \mathrm{Cu}$ sheet by sintering, cold rolling and re-sintering," International Journal of Refractory Metals and Hard Materials, vol. 28, no. 2, pp. 198-200, 2010.

[10] Z. Wang, X. Li, J. Zhu, F. Mo, C. Zhao, and L. Wang, "Dynamic consolidation of $\mathrm{W}-\mathrm{Cu}$ nanocomposites from $\mathrm{W}-\mathrm{CuO}$ mixture," Materials Science and Engineering: A, vol. 527, no. 21-22, pp. 6098-6101, 2010.

[11] M. Amirjan, N. Parvin, and K. Zangeneh-Madar, "Mutual dependency of mechanical properties and contiguity in $\mathrm{W}-\mathrm{Cu}$ composites," Materials Science and Engineering: A, vol. 527, no. 26, pp. 6922-6929, 2010. 
[12] D. Z. Wang, B. Z. Yin, A. K. Sun, X. L. Li, C. K. Qi, and B. H. Duan, "Fabrication of Mo-Cu composite powders by heterogeneous precipitation and the sintering properties of the composite compacts," Journal of Alloys and Compounds, vol. 674, pp. 347-352, 2016.

[13] G. Krishnan, M. A. Verheijen, G. H. Brink, G. Palasantzas, and B. J. Kooi, "Tuning structural motifs and alloying of bulk immiscible $\mathrm{Mo}-\mathrm{Cu}$ bimetallic nanoparticles by gas-phase synthesis," Nanoscale, vol. 5, p. 5375, 2013.

[14] V. D. P. Martinez, C. Aguilar, J. Marin, S. Ordonez, and F. Castro, "Mechanical alloying of $\mathrm{Cu}-\mathrm{Mo}$ powder mixtures and thermodynamic study of solubility," Materials Letters, vol. 61, no. 4, pp. 929-933, 2007.

[15] X. Wang, L. X. Hu, H. Wang, and E. D. Wang, "Microstructure and properties of $\mathrm{Mo}-50 \% \mathrm{Cu}$ alloy by mechanical milling and pressure-assisted solid state sintering," Rare Metal Materials and Engineering, vol. 40, no. 5, p. 902, 2011.

[16] X. X. Wei, J. C. Tang, N. Ye, and H. O. Zhuo, "A novel preparation method for $\mathrm{W}-\mathrm{Cu}$ composite powders," Journal of Alloys and Compounds, vol. 661, pp. 471-475, 2016.

[17] A. K. Sun, D. Z. Wang, Z. Z. Wu, L. H. Li, J. S. Wang, and B. H. Duan, "Microwave-assisted synthesis of Mo-Cu nanopowders at an ultra-low temperature and their sintering properties," Materials Chemistry and Physics, vol. 148, no. 3, pp. 494-498, 2014.

[18] S. Tan, Nonferrous Materials, Metallurgical Industry Press, Beijing, China, 1993.

[19] M. Ardestani, H. R. Rezaie, H. Arabi, and H. Razavizadeh, "The effect of sintering temperature on densification of nanoscale dispersed W-20-40\%wt Cu composite powders," International Journal of Refractory Metals and Hard Materials, vol. 27, no. 5, pp. 862-867, 2009.

[20] X. L. Zhou, A. H. Zou, X. Z. Hua, J. Y. Zhang, and Y. H. Rao, "Sintering characteristics of mechanically alloyed $\mathrm{Mo}-\mathrm{Cu}$ powder," Transactions of Materials and Heat Treatment, vol. 30, no. 3, p. 24, 2009.

[21] D. Z. Wang, X. J. Dong, P. Zhou, A. K. Sun, and B. H. Duan, "The sintering behavior of ultra-fine $\mathrm{Mo}-\mathrm{Cu}$ composite powders and the sintering properties of the composite compacts," International Journal of Refractory Metals and Hard Materials, vol. 42, no. 1, pp. 240-245, 2014.

[22] P. A. Chen, Q. Shen, G. Q. Luo, M. J. Li, and L. M. Zhang, "The mechanical properties of $\mathrm{W}-\mathrm{Cu}$ composite by activated sintering," International Journal of Refractory Metals and Hard Materials, vol. 36, no. 6, pp. 220-224, 2013. 


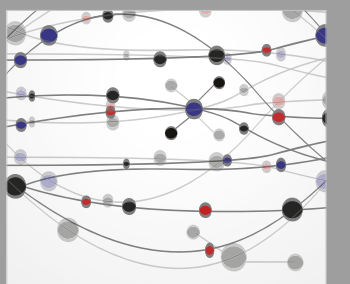

The Scientific World Journal
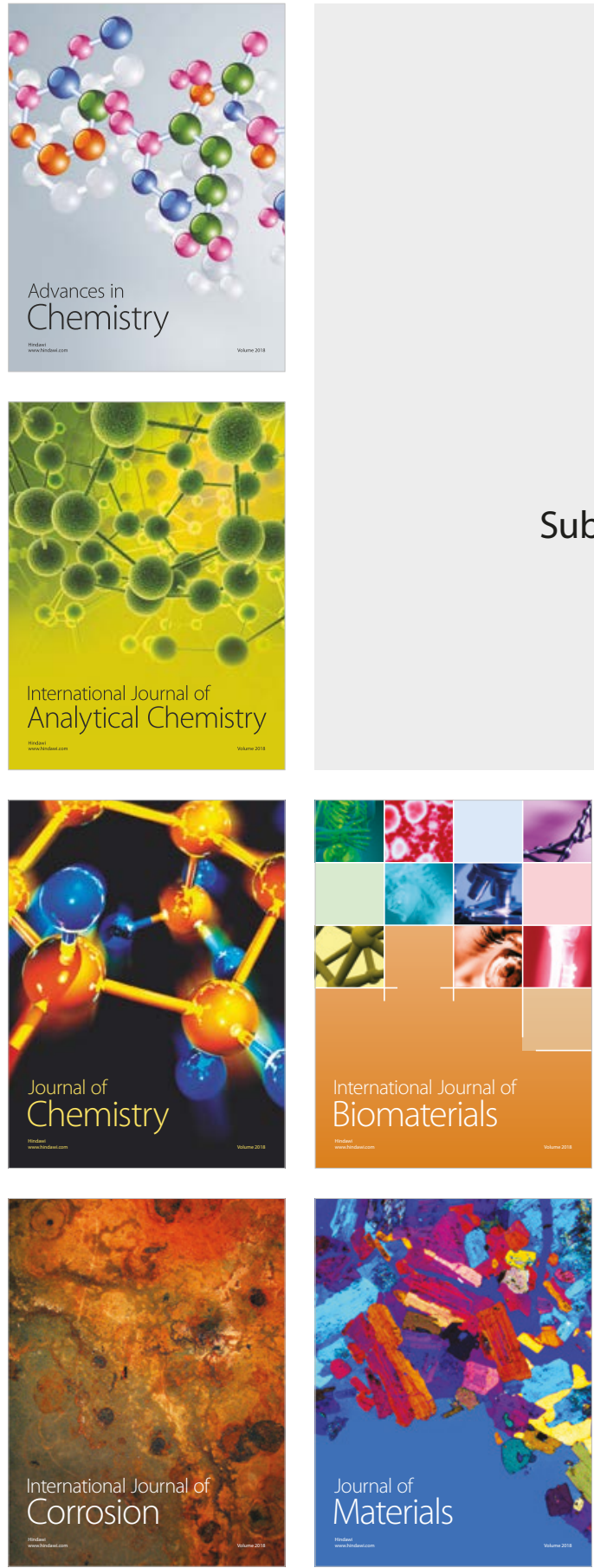

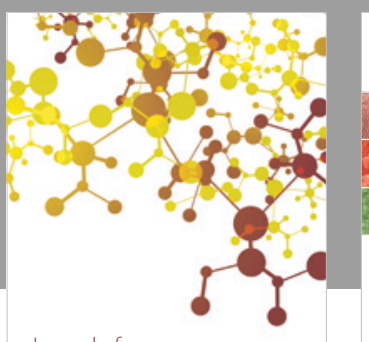

Journal of

Applied Chemistry
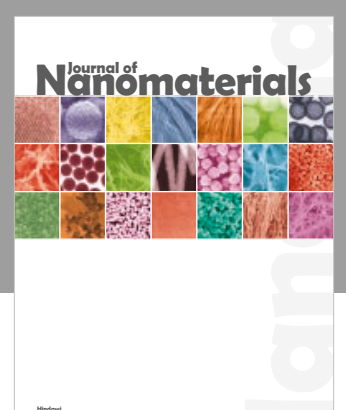

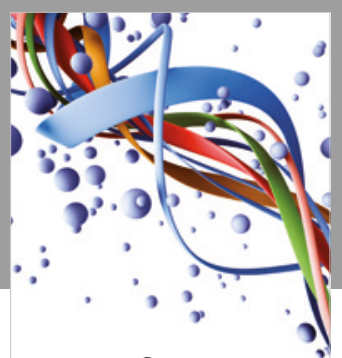

Scientifica

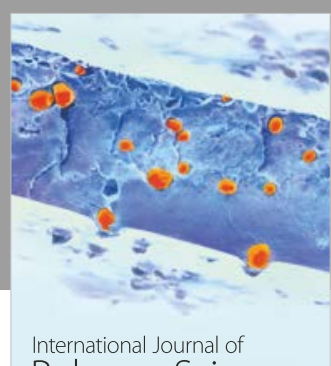

Polymer Science

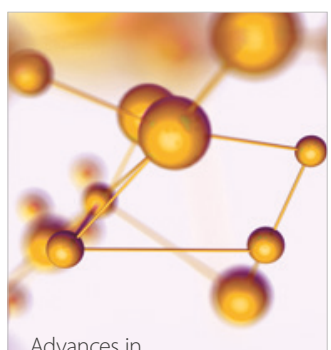

Physical Chemistry
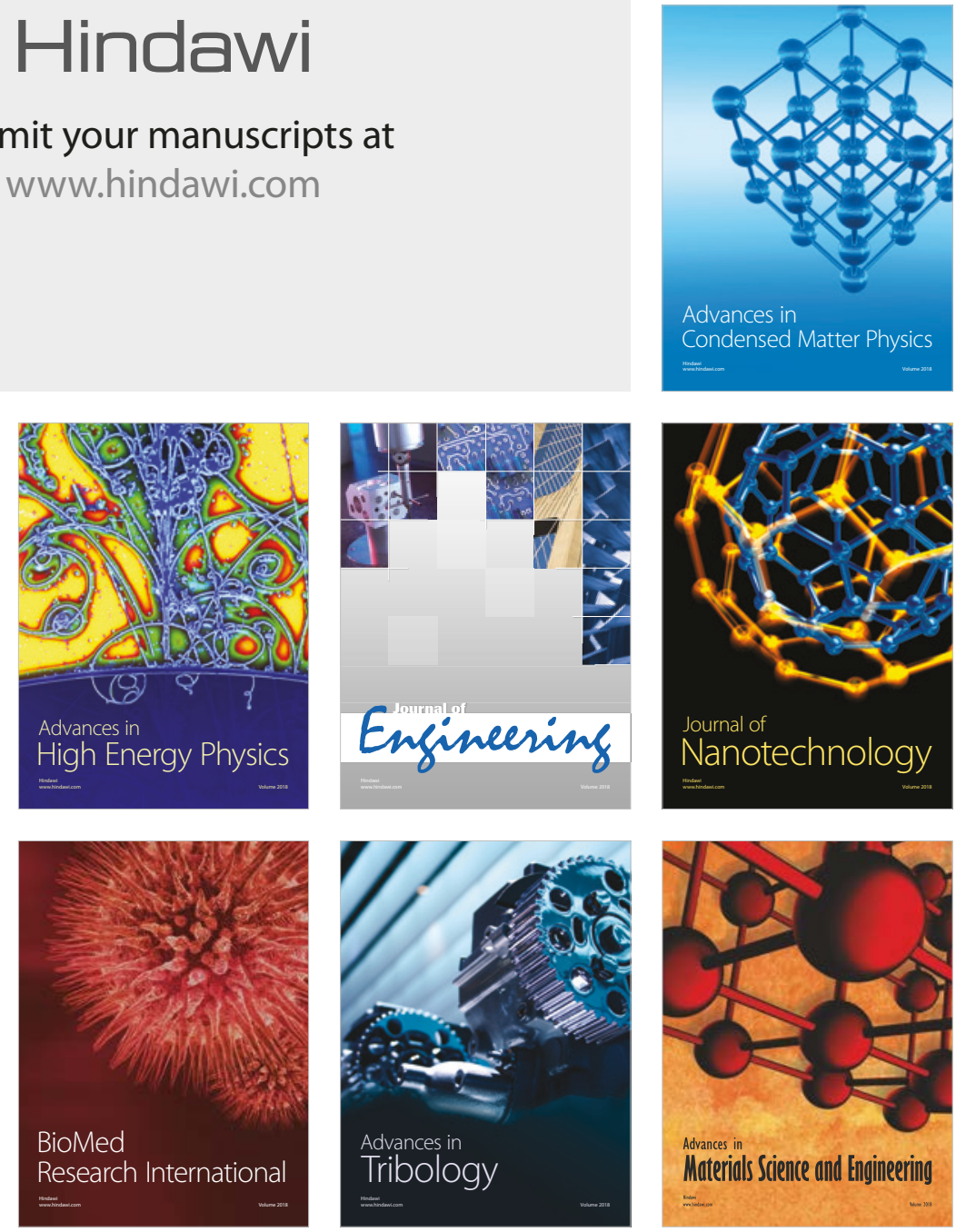